
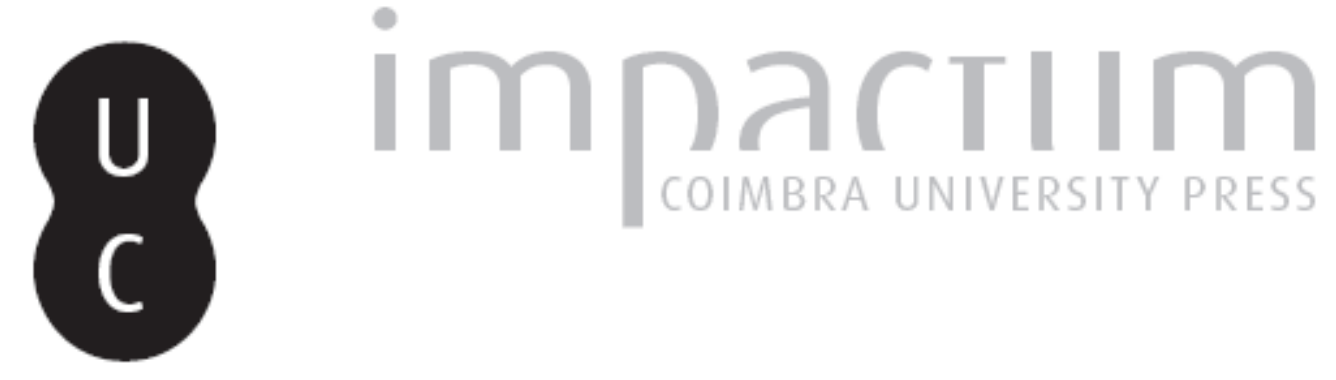

\title{
A propósito de uma crítica de António M. Monge Soares: ou de como, por vezes, não se deve confiar nos críticos
}

Autor(es): $\quad$ Alarcão, Jorge de

Publicado por: Faculdade de Letras da Universidade de Coimbra

URL persistente:

URI:http://hdl.handle.net/10316.2/37814

DOI:

DOI:http://dx.doi.org/10.14195/1647-8657_44_8

Accessed : $\quad$ 26-Apr-2023 13:25:17

A navegação consulta e descarregamento dos títulos inseridos nas Bibliotecas Digitais UC Digitalis, UC Pombalina e UC Impactum, pressupõem a aceitação plena e sem reservas dos Termos e Condições de Uso destas Bibliotecas Digitais, disponíveis em https://digitalis.uc.pt/pt-pt/termos.

Conforme exposto nos referidos Termos e Condições de Uso, o descarregamento de títulos de acesso restrito requer uma licença válida de autorização devendo o utilizador aceder ao(s) documento(s) a partir de um endereço de IP da instituição detentora da supramencionada licença.

Ao utilizador é apenas permitido o descarregamento para uso pessoal, pelo que o emprego do(s) título(s) descarregado(s) para outro fim, designadamente comercial, carece de autorização do respetivo autor ou editor da obra.

Na medida em que todas as obras da UC Digitalis se encontram protegidas pelo Código do Direito de Autor e Direitos Conexos e demais legislação aplicável, toda a cópia, parcial ou total, deste documento, nos casos em que é legalmente admitida, deverá conter ou fazer-se acompanhar por este aviso.

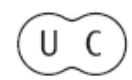




\section{CONIMBRIGA}

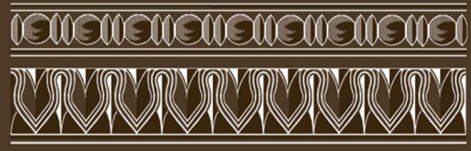

INSTITUTO DE ARQUEOLOGIA

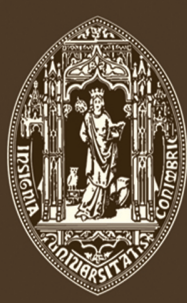

VOLUME XLIV • 2005

FACULDADE DE LETRAS UNIVERSIDADE DE COIMBRA 


\section{A PROPÓSITO DE UMA CRÍTICA DE ANTÓNIO M. MONGE SOARES}

Ou de como, por vezes, não se deve confiar nos críticos

JoRGE DE ALARCÃo

Qualquer autor que publique obra de tomo ou artigo de revista deve sujeitar-se à crítica de quem o lê. A crítica, quando honesta, é bemvinda - pois corrige erros ou imprecisões, acrescenta dados ou contrapõe, às interpretações do autor, outras interpretações que podem ser fundadas e obrigar a uma revisão do que foi dito. A crítica, quando honesta, é igualmente útil aos leitores, pois ajuda a formar juízo acertado sobre o mérito - ou a falta dele - de um trabalho publicado.

As críticas, quando desonestas, são, porém, reprováveis. Consideramos desonestas as que pretendem fazer passar por excelente uma obra medíocre ou as que, inversamente, pretendem apresentar como medíocre ou indigna de confiança uma obra que, pela sua seriedade ou originalidade ou pela quantidade e qualidade dos dados com que o conhecimento se acrescenta e renova, são merecedoras de louvores - ainda que, no segundo caso, possam e devam ser corrigidos alguns erros ou omissões de que mesmo as melhores obras frequentemente padecem ou possam ser contrapostas, às interpretações do autor, outras interpretações dos críticos.

Vem isto a propósito da crítica que António M. Monge Soares (daqui em diante referido pelas iniciais M.S.) fez, no n. ${ }^{\circ} 13$ da $2^{\mathrm{a}}$ série da revista Al-madan, à obra de Maria Conceição Lopes (daqui em diante referida pelas iniciais M.C.L.), A cidade romana de Beja. Percursos e debates acerca da civitas de Pax Iulia. Subintitulou M.S. os seus 
comentários desta forma: "ou de como, por vezes, não se deve confiar em levantamentos arqueológicos".

Diz M.S.: "Das 27 entradas do Catálogo de Sítios referentes à freguesia de Vila Verde de Ficalho, dez delas (com benevolência), isto é, cerca de $40 \%$, contêm erros, alguns deles bastante grosseiros".

O sublinhado é nosso, para chamarmos a atenção para o fariseísmo do crítico, que pretende fazer passar por benevolente uma crítica contundente e, a nosso ver, de má-fé.

Acrescenta M.S.: "não é de admirar que esta percentagem seja também válida para as outras freguesias do distrito de Beja, dadas as incorrecções detectadas nas descrições dos pouquíssimos sítios que conhecemos com precisão fora da freguesia de Vila Verde de Ficalho..." Uma vez mais, é nosso o sublinhado.

Parece-nos irrelevante a imprecisão dos cerca de $40 \%$, quando, afinal, são $37 \%$ - ainda que, num catálogo de 632 sítios, a diferença de $37 \%$ para $40 \%$ se traduza num número não despiciendo de estações afectadas pelos supostos erros. Mais importante nos parece que, falando M.S. de "erros, alguns deles bastante grosseiros", não tenha tido o cuidado de indicar qual é a percentagem dos erros que considera "bastante grosseiros" e qual é a percentagem dos que não classifica como tais. Ficamos sem saber se "erros bastante grosseiros" afectam $37 \%$ ou $3,7 \%$ do catálogo. E como, no passo acima transcrito, relativo às outras freguesias do distrito de Beja, M.S. não fala de "erros, alguns deles bastante grosseiros", mas de "incorrecções", a desonestidade da crítica torna-se ainda mais evidente. Admitindo a validade ou utilidade do uso da estatística no caso em apreço, a objectividade e imparcialidade recomendariam a M.S. que distinguisse incorrecções, erros e erros bastante grosseiros e que, para cada uma destas suas categorias, indicasse as respectivas percentagens. O crítico que se apresenta como benevolente não diz, afinal, se os "erros" e os "erros bastante grosseiros" afectam $39 \%$ das descrições e se as incorrecções atingem $1 \%$ ou vice-versa.

Pretende M.S. que há "erros, alguns deles bastante grosseiros", em $40 \%$ dos 27 sítios registados por M.C.L. na freguesia de Vila Verde de Ficalho. E pretende também ter encontrado "incorrecções" nas descrições dos "pouquíssimos" sítios que conhece com precisão no distrito de Beja fora daquela freguesia. Os "pouquíssimos" sítios são 6 num universo de 605 estações (com efeito, se subtrairmos 27 sítios da freguesia de Vila Verde de Ficalho aos 632 registados no catálogo de M.C.L., obteremos 605). Quer dizer: tendo verificado "incorrecções" em 6 de 
605 estações, M.S. permite-se sugerir aos leitores que cerca de $40 \%$ dos sítios do catálogo de M.C.L. estão afectados por erros, alguns deles bastante grosseiros. Como sofisma ou paralogismo, não podíamos encontrar melhor: imprecisões são transformadas em "erros, alguns deles bastante grosseiros" e a verificação de "incorrecções" em menos de $1 \%$ de 605 sítios conduz M.S. à conclusão de que em 40\% dos sítios fora da freguesia de Vila Verde de Ficalho pode haver erros, eventualmente bastante grosseiros.

Benevolente para com M.C.L. e muito preocupado com os possíveis leitores e utilizadores da obra, a quem endereça uma advertência, M.S. conclui: "Perdeu-se uma excelente oportunidade de ficar disponível para a comunidade científica uma base de dados de sítios proto-históricos e romanos, na área da civitas de PAX IVLIA, que pudesse ser manejada com um mínimo de confiança". Pela nossa parte, diremos que M.S. perdeu uma excelente oportunidade de fazer uma crítica justa, esclarecedora e que merecesse a confiança dos leitores. Construiu, no ar, um castelo tão frágil como os de cartas. Exagera, desvirtua muitas vezes o que M.C.L. escreveu, carrega em algumas imperfeições para fazer delas erros, disfarça a pequenez de certas observações críticas com a grandeza do adjectivo "grosseiro".

Afirma M.S. que, embora seja diminuta a amostra de sítios que conferiu para verificar a correcção ou os erros de M.C.L., tal amostra "poderá, no entanto, ser considerada aleatória e, por conseguinte, representativa do inventário realizado".

Tendo M.C.L. inventariado 632 sítios de 50 freguesias de 10 concelhos dos distritos de Beja e Évora, M.S. verificou a totalidade das 27 fichas de inventário da freguesia de Vila Verde de Ficalho e, fora desta, apenas 6: 1 de uma freguesia do concelho de Moura, 1 de uma freguesia do concelho de Beja e 4 de duas freguesias do concelho de Serpa (em que a freguesia de Vila Verde de Ficalho também se integra). Ou M.S. ignora o significado de amostra aleatória e a técnica a que deve obedecer uma amostragem dessa natureza para ser minimamente credível (ou para tornar minimamente credíveis quaisquer generalizações) ou pretende iludir o leitor, lançando-lhe poeira aos olhos e fazendo passar por aleatória uma amostragem que, de aleatória, nada tem. No primeiro caso, tratar-se-á de ignorância; no segundo, de desonestidade. Uma obra da dimensão da de M.C.L. não pode julgar-se conferindo apenas o que nela se reporta ao modesto tamanho de uma freguesia. 
Se M.S. eventualmente nos retorquir que verificou muito mais fichas de muito mais lugares de muitas mais freguesias, perguntar-lhe-emos: nessas outras fichas encontrou erros? Se encontrou, foi por benevolência que não os referiu? Se não encontrou, por que razão não diz em quantas fichas verificadas não encontrou erros?

Antes de examinarmos os casos em que M.S. pretende que há incorrecções ou mesmo erros, e alguns deles bastante grosseiros, diremos por que razão não é legítimo estender, à totalidade dos 632 sítios inventariados por M.C.L., uma percentagem deduzida dos 27 sítios da freguesia de Vila Verde de Ficalho. Repetimos que o inventário de M.C.L. cobre 50 freguesias de 10 concelhos.

Ora o que se passou com o catálogo de sítios da freguesia de Vila Verde de Ficalho foi que M.C.L., por respeito pelo que podemos chamar (ou frequentemente se chama) "propriedade científica", reduziu ao mínimo a prospecção e a verificação naquela freguesia do concelho de Serpa, à qual M.S. tem dado particular atenção. A M.S. se deve a descoberta ou divulgação da maioria das estações arqueológicas da freguesia, não só proto-históricas e romanas, como pré-históricas.

Tendo sido, em 1995, solicitada pela Câmara Municipal de Serpa para elaborar a carta arqueológica do concelho, M.C.L. associou, aos trabalhos de prospecção, Pedro C. Carvalho e Sofia M. Gomes. O resultado foi publicado, em 1997, num livro intitulado Arqueologia do concelho de Serpa. Da "Apresentação" que escrevemos para essa obra, respigamos:

"Em cinco meses de trabalho, Pedro Carvalho e Sofia Gomes, sob orientação de M. Conceição Lopes, identificaram três centenas de moradas [na realidade, 322 sítios cartografados, incluindo 237 inéditos] que o delgado chão alentejano mal oculta e todavia jaziam deslembradas. Realizaram um trabalho que nos parece meritório. Não terão visto tudo. Mas quem pode pretender ter feito um inventário exaustivo do património arqueológico? Sempre um pastor, um lavrador, um caçador, que são os homens mais chegados à terra, descobrirão novos lugares, denunciados por telhões ou por escórias, por louças estilhaçadas ou moedas".

Transcrevendo o que em 1997 dissemos (pecando por omissão dos "pesquisadores de tesouros" que se multiplicam, impunes, por todo o Alentejo), introduzimos um sublinhado que não está no original, para explicitarmos que usámos uma fórmula de modéstia: o parece não deve 
sugerir uma dúvida, mas a reserva de quem não gosta de enfatizar os méritos próprios nem de proclamar, com imodéstia, os daqueles que instruiu - aqueles a quem reconheceu competência e seriedade e a cujo trabalho continua a dar apoio, lendo com espírito crítico e sem falsos elogios o que vão produzindo.

Na citada Arqueologia do concelho de Serpa, os autores escreveram: "Na área de Vila Verde de Ficalho, os trabalhos de prospecção restringiram-se aos sítios sobre os quais havia referências bibliográficas e a alguns de que obtivemos informação oral, na medida em que contávamos com a colaboração de Monge Soares, que nos forneceu os dados necessários relativos às estações desta freguesia das quais se reproduz a descrição e a classificação".

Na obra A cidade romana de Beja. Percursos e debates acerca da civitas de Pax Iulia, M.C.L. aproveitou o que havia sido escrito em Arqueologia do concelho de Serpa. Por aquilo que pode ser considerado, não uma "coutada" de M.S. mas uma sua (legítima) "propriedade científica”, M.C.L. não concedeu à freguesia de Vila Verde de Ficalho a mesma atenção que deu às outras dos concelhos de Aljustrel, Beja, Cuba, Ferreira do Alentejo, Moura, Serpa e Vidigueira (e a algumas estações dos concelhos de Alvito, Portel e Viana do Alentejo). Ressalve-se que nem todas as freguesias destes concelhos foram prospectadas com a mesma intensidade, pelo que numas, mais do que noutras, podemos antecipar a descoberta de mais sítios do que os inventariados (e, nalgumas freguesias, mesmo muito mais sítios). Aliás, é considerável o número de sítios descobertos por M.C.L. posteriormente à publicação da sua tese. Importa, pois, salientar que, tendo sido a freguesia de Vila Verde de Ficalho objecto de menos atenção, não é legítimo suspeitar que se encontre, nas demais 49, a mesma suposta percentagem dos mesmos supostos erros e incorrecções. Pelo contrário, é legítimo supor que se encontrarão menos erros (ou supostos erros) e menos imprecisões (ou supostas imprecisões).

Mas, pondo de lado a ilegitimidade e gratuidade da suspeita com que M.S. pretende negar a qualidade e fiabilidade do catálogo de M.C.L., devemos perguntar-nos: há na obra de M.C.L. tantas incorrecções e tantos erros quantos os que M.S. aponta? Será que tais incorrecções e erros têm suficiente gravidade para justificar a afirmação de que a obra não pode ser manejada com um mínimo de confiança? Por uma questão de clareza, dividiremos em categorias as incorrecções e os erros que M.S. detecta ou pretende ter detectado - pois, mesmo considerando 
pequenidades muitas das observações de M.S., queremos desmisturar o que na crítica se baralha e fazer uma análise bem explicada.

1. Apresentação, como sítios arqueológicos, de lugares onde se verificaram achados singulares ou isolados

Se entendemos bem, M.S. contesta a inclusão, no catálogo, de sítios que correspondem a achados singulares e pouco significativos: Sabrosa (n. ${ }^{\circ} 406$ ), com um fragmento de tégula e Ferragial do Cubo (n. ${ }^{\circ} 412$ ), com um peso de tear. Deve dizer-se, em abono da verdade, que M.C.L. regista isso mesmo: que se trata de achados isolados. $\mathrm{E}$, nos dois casos, considera os sítios indeterminados do ponto de vista funcional.

Os achados isolados põem, a qualquer prospector, um problema metodológico: devem ou não ser incluídos numa carta arqueológica?

Pelo que respeita ao fragmento de tégula, podemos supor que alguém (um arqueólogo? um pastor?) o encontrou noutro local e o recolheu; mas, caminho andado, perguntou-se para que serviria o fragmento e ali mesmo onde teve esse pensamento deitou fora o que agora lhe pareceu sem préstimo. Ou imaginar que o fragmento de tégula, aqui, é apenas o vestígio arqueológico de um transporte: de um carro de bois carregado de telhas, a caminho de uma villa que se construía, caíu uma tégula que ficou ali partida e perdida. Ou que, feito o transporte num dia chuvoso de inverno, o carro se atolou nalguma poça e o carreiro tirou da carga uma tégula e a utilizou como calço para retirar o carro do atoleiro. Ou pensar que o fragmento pertenceu a uma tégula que, em época romana, foi base ou tecto de um cortiço de abelhas. Ou que serviu para cobrir a cabeceira de uma sepultura da qual, hoje, se não observam vestígios. Ou que a tégula, com outras tégulas que agora não são visíveis à superfície, serviu de cobertura a um modesto tugurium, dependente de villa ou casal - tugurium de que se encontrariam outros vestígios se fosse escavado. Etc., etc.

Ao registar este "insignificante" achado (como ao registar o isolado peso de tear), M.C.L. teve certamente alguma suspeita de que ali poderá haver mais alguma coisa. E decidiu incluir o sítio no seu catálogo até como chamada de atenção a outros arqueólogos aos quais se recomenda que revisitem o lugar: noutra ocasião, não se tornará visível algo mais? 
Seja como for - ou seja qual for a opção metodológica que se tome relativamente aos achados isolados - a inclusão dos dois sítios de Sabrosa e Ferragial do Cubo não pode, senão com muitas dúvidas ou reticências, ser classificada de erro; e nunca o poderá ser como erro grosseiro. Mas diga-se também, em abono da verdade, que M.C.L., no caso de Sabrosa, peca por omissão, pois, registando "achado isolado", não diz que achado foi esse e temos de recorrer a M.S. para sabermos que se trata de um fragmento de tégula. Neste caso concreto, se é exagero falar de erro, é pelo menos prestável a informação de M.S. de que o achado foi o de um fragmento de tégula.

Diga-se também, por outro lado, e obedecendo à norma da imparcialidade, que não se pode acusar M.C.L. de ter inflacionado a sua carta arqueológica, alcançando o número global de 632 estações à custa de achados isolados. Contámos, no seu catálogo, menos de uma dúzia de estações que, afinal, correspondem a achados isolados.

A estes casos acrescem os de inscrições achadas em aldeias ou vilas nas quais não se registaram, até agora, outros vestígios arqueológicos. Nestas circunstâncias, podemos duvidar se as inscrições não terão sido trazidas, para essas aldeias ou vilas, de alguma estação arqueológica dos arredores (ou, eventualmente, até distante). Consideramos correcta, porém, a opção metodológica de atribuir um número próprio de catálogo a esses lugares onde as inscrições se encontram (ou encontraram) quando se não pode identificar com segurança (ou, pelo menos, com grande probabilidade) o local onde tais inscrições, na época romana, estavam (ou estariam).

2. Repetições de um mesmo sítio com números diferentes de catálogo

Observa M.S. - e neste caso, justamente - que o referido sítio de Sabrosa surge no catálogo com o n. 406 e é repetido mais adiante, com o n. ${ }^{\circ}$ 430. O mesmo ocorreria com o sítio de Santa Margarida 1 (n. ${ }^{\circ}$ 396): seria uma repetição do sítio de Santa Margarida 2 (n. ${ }^{\circ} 352$ ).

No primeiro caso trata-se efectivamente de uma repetição que, sendo lamentável, não engana ninguém, visto que as coordenadas geográficas dadas para Sabrosa são exactamente as mesmas em 406 e 430. No segundo caso, que peca por falta de clareza da exposição, M.C.L. designa como Santa Margarida $1 \mathrm{um}$ povoado que considera do Bronze 
Final e da $1^{\text {a }}$ Idade do Ferro e como Santa Margarida 2 uma villa romana. Atendendo à grande proximidade do povoado e da villa, deveríamos considerar que se trata de um único sítio? A opção feita é discutível, mas não nos parece que um desdobramento (passível de crítica em função de outra opção metodológica) deva ser apelidado de repetição ou erro e, muito menos, de erro grosseiro. De qualquer forma, M.C.L. remete para Arqueologia do concelho de Serpa, p. 43, onde as dúvidas podem ser esclarecidas.

3. Ausência de registo, na carta geral da fig. 8, de sítios incluídos no catálogo

Refere-se M.S. aos sítios inventariados nas freguesias de Santo Aleixo da Restauração, Safara e Sobral da Adiça, no concelho de Moura. A explicação, que se acha devidamente expressa, reside em que M.C.L. não confirmou, no terreno (com raras excepções), os sítios do concelho de Moura. Por considerar que esta área ainda pertencia ao territorium da civitas de Pax Iulia, realizou o inventário dos sítios a partir da bibliografia existente mas não o confirmou em prospecção própria. Por isso os sítios não levam indicação de coordenadas - e, como consequência, não foram cartografados. A ausência da representação cartográfica não é, pois, incorrecção ou erro, mas exigência de rigor. Se M.S. tivesse lido com atenção o catálogo, teria verificado que há outros sítios, noutros concelhos, incluídos no inventário mas não cartografados pela mesma razão.

\section{Erros de representação cartográfica ou de posicionamento}

Refere M.S. que, nas figuras 8 e 9 da obra de M.C.L., há erro de localização de Rosal de la Frontera, - povoação andaluza que naquelas cartas está situada em Portugal - e erro de localização do povoado do Laço, que fica na margem esquerda do Guadiana e aparece cartografado na direita.

Sem querermos absolver M.C.L. de erros manifestos (como o da posição de Rosal de la Frontera), não deixaremos de insistir em que só por má-fé se pode condenar um catálogo por erros que se não contêm nele, mas só na representação cartográfica que o acompanha. Aliás, nin- 
guém que procure os lugares no terreno ou utilize os dados de M.C.L. para fazer a sua própria base de dados se servirá daquelas representações cartográficas mas das coordenadas geográficas apresentadas pela autora. Quanto ao povoado do Laço, qualquer desnorte que possa surgir do erro cartográfico de M.C.L. será corrigido pela carta de pormenor, na escala 1:25000, apresentado em Arqueologia do concelho de Serpa, obra para a qual M.C.L. remete e onde a posição do povoado está correctamente assinalada.

Acrescenta M.S. que o sítio de Ferragial do Cubo (n. ${ }^{\circ} 412$ ) se não encontra "próximo de Vila Verde de Ficalho", mas na própria localidade, "onde actualmente existe o campo de futebol..." Mas não diz o autor se as coordenadas estão (ou não) erradas... Projectando as coordenadas apresentadas por M.C.L. caímos, exactamente, no campo de futebol!

M.S. acusa M.C.L. de, em Arqueologia do concelho de Serpa, ter cartografado mal o sítio de Casa Branca 1. A representação cartográfica no mapa da p. 36 está correcta. Na "ficha de sítio" houve uma lamentável troca de números na indicação das coordenadas.

Se, nas cartas de síntese, apresentadas em A cidade romana de $B e j a$, pode haver (ou há mesmo) alguns erros de localização (ou de sinais diacríticos), tais erros são manifestamente de reduzida importância - pois quem quiser procurar os sítios ou registá-los numa base de dados não utilizará as cartas, mas as coordenadas geográficas dadas por M.C.L. Quanto a estas, o único erro até agora detectado nos 632 sítios do Catálogo é o de Casa Branca 1 a que acabámos de referir-nos.

\section{Erros na classificação funcional dos sítios}

A ficha de inventário de M.C.L. inclui, para cada sítio, uma classificação funcional: indica se se trata de villa, de casal, de povoado, etc.

A classificação funcional (como, aliás, a classificação cronológica) de um sítio nem sempre é óbvia a partir de vestígios observáveis à superfície e sem uma escavação. Apesar de tudo, consideramos que vale a pena correr o risco, desde que a proposta seja muito ponderada. Nenhuma carta arqueológica merece verdadeiramente esse nome nem estudo nenhum se pode considerar de arqueologia da paisagem ou de povoamento se se limitar a "pontos no mapa" (dots on maps como os ingleses os designam), classificando todos os sítios com a mesma e 
única indicação de habitat e cartografando todos os lugares (tanto uma villa como um tugurium) com o mesmo sinal diacrítico. As cartas arqueológicas que nos últimos anos se têm publicado em Portugal têm adoptado - e, a nosso ver, ainda bem - essa norma de propôr uma classificação funcional dos sítios.

As classificações funcionais propostas por M.C.L. para os 632 sítios que regista foram sempre muito ponderadas e tiveram em conta vários parâmetros, aliás bem explicitados pela autora. Em muitos casos, quando as probabilidades ou possibilidades de erro se lhe afiguravam grandes, M.C.L. acrescentou uma interrogação: villa? casal?

São poucos os casos em que M.S. diverge de M.C.L. na proposta de classificação funcional. E, nesses poucos casos, não se pode falar de erros, mas apenas de divergências de opinião - não nos parecendo mais credível a interpretação proposta por M.S. do que a interpretação de M.C.L.

Quanto a Estercadinha (n. $\left.{ }^{\circ} 420\right)$, M.S. contesta a classificação como villa dado que - diz - a área de dispersão de vestígios não ultrapassa a dimensão da copa de uma azinheira. Omite o crítico (ou oculta) que M.C.L. classifica o sítio como casal e que só em comentário final admite, prudentemente, que possa tratar-se de uma villa ocupada só no Alto Império e de reduzida dimensão. Muitas das primeiras villae do Alentejo foram estabelecimentos muito modestos, a ponto de nos devermos perguntar se lhes convém o nome de villae. Algumas foram depois abandonadas. Outras foram reconstruídas com outra dimensão, nem sempre no mesmo exacto lugar.

M.S. inclui, entre os erros de M.C.L., a classificação funcional de Ermida de Nossa Senhora das Pazes (n. ${ }^{\circ}$ 423). M.S. hesita entre a classificação como villa e a classificação como casal, embora se incline mais para a segunda. M.C.L. classifica o sítio como villa, mas com expressa interrogação, que reforça, aliás, dizendo: "Temos muitas dúvidas na classificação que atribuímos a este sítio". Não há, pois, erro nenhum, visto que não se faz uma afirmação mas se exprime uma dúvida - da qual, aliás, ambos os autores partilham.

\section{Erros nas descrições dos sítios ou do que neles se vê}

Relativamente ao povoado do Laço (n. ${ }^{\circ} 240$ ), contesta M.S. a informação de que tem uma muralha com cerca de $2 \mathrm{~m}$ de largura e diz 
que em nenhum lugar pôde observar tal medida. Não concretiza M.S. a dimensão do suposto erro. O leitor fica sem saber se M.S. mediu, no máximo, $1,85 \mathrm{~m}$ ou $1,90 \mathrm{~m}$ (caso em que a discrepância não seria grande, visto que M.C.L. fala de "cerca de $2 \mathrm{~m}$ ") ou apenas $1 \mathrm{~m}$ (caso em que a discrepância seria grande e, se déssemos mais confiança a M.S. que a M.C.L., deveríamos falar de erro). Considera-se irrelevante a aproximação ao centímetro. Ou, mais do que irrelevante, pedante ou falsamente rigorosa, visto que uma muralha de xisto, sem argamassa de cal, não tem a mesma largura na base e no topo nem a mantém constante em toda a extensão perimetral.

Relativamente a Passo Alto (n. ${ }^{\circ}$ 407), assinala M.S. o erro de M.C.L., que atribui ao povoado "dois recintos amuralhados, fosso e barreira de pedras fixadas" (estas últimas, noutro passo da mesma "ficha", designadas por "cavalos de frisa", segundo terminologia corrente). Aqui é manifesto o erro. Aliás, em Arqueologia do concelho de Serpa, M. Conceição Lopes, Pedro C. Carvalho e Sofia M. Gomes anotam, não dois recintos amuralhados, mas "um sistema defensivo duplo - muralha e "cavalos de frisa".

M.S. contesta a afirmação de que o sítio de Santa Margarida é o único povoado de planície do Bronze Final, que se encontra em todo o território examinado por M.C.L. e cita Casa Branca 1 como povoado do Bronze Final do Sudoeste também de planície. Na realidade, o que M.C.L. diz é que, tendo sido o sítio de Santa Margarida também ocupado na Idade do Ferro, é o único povoado desta época, de planície, que encontrou no território examinado.

Ao contrário do que pretende M.S., ainda a propósito de Santa Margarida 2, são vários os tijolos com marca EX OF VINCINTI que terão sido recolhidos no local. Se Fragoso de Lima mencionou apenas um, M.C.L. viu vários, em 1997, no Palácio de Ficalho, onde lhe foi dito que provinham de Santa Margarida.

Relativamente a Ermida de Nossa Senhora das Pazes 2 (n. $\left.{ }^{\circ} 424\right)$ M.S. denuncia o que, efectivamente, é um erro - pois M.C.L. atribuiu a este sítio (uma necrópole tardo-romana), "alguns fragmentos cerâmicos e uma amoladeira" que foram encontrados noutro lugar.

Quanto a Assento do Chico Roupa 2 (n. $\left.{ }^{\circ} 429\right)$, é justa a observação de M.S.: foram dois os esqueletos desta necrópole datados por radiocarbono e as sepulturas não continham qualquer espólio. 


\section{Erros na classificação cronológico-cultural dos sítios}

Por classificação cronológico-cultural entendemos o que a maioria dos arqueólogos (ou mesmo todos) entende: atribuição de um sítio a um (ou vários) dos grandes períodos que os arqueólogos habitualmente distinguem - por exemplo, Bronze Final, $1^{\text {a }}$ Idade do Ferro, $2^{\text {a }}$ Idade do Ferro ou, para a época romana, Alto Império, Baixo Império, Tardo-Romano, etc.

Pretende M.S. que M.C.L. tem incorrecções na classificação cronológico-cultural, e refere os sítios de Azenha da Misericórdia (n. $\left.{ }^{\circ} 345\right)$ e S. Brás 1 (n. 346).

Quanto a Azenha da Misericórdia, que, segundo M.C.L., tem uma “ocupação desde o Bronze Final até à II Idade do Ferro, com ocupação na época romana”, diz M.S. que a afirmação não é totalmente correcta (aqui, honestamente, abstem-se de falar de erro) porque existem três ocupações: Bronze Final, II ${ }^{\mathrm{a}}$ Idade do Ferro e Época Romana, tendo esta de ser considerada como vestigial". A leitura do que M.C.L. escreveu sugere ocupação contínua, desde o Bronze Final à época romana. Sugere, pois - ainda que o não afirme explicitamente - que o sítio foi também habitado na $1^{\mathrm{a}}$ Idade do Ferro. Poderá dizer-se que se trata de suposição infundada, visto que não se recolheram, à superfície, materiais claramente atribuíveis à $1^{\mathrm{a}}$ Idade do Ferro. No estado dos nossos conhecimentos não é possível assegurar que determinadas cerâmicas, geralmente atribuíveis ao Bronze Final, não se continuaram a fabricar e usar na $1^{\mathrm{a}}$ Idade do Ferro; nem é ainda muito clara a distinção entre uma $1^{\mathrm{a}}$ e uma $2^{\mathrm{a}}$ Idade do Ferro - ou a distinção entre materiais exclusivos de uma ou outra dessas idades. A afirmação de M.S. de que o sítio não foi ocupado na $1^{\mathrm{a}}$ Idade do Ferro (se é isso que pretende dizer) e a afirmação de M.C.L. de que houve ocupação contínua do Bronze Final à época romana são ambas meras suposições - uma tão válida (ou tão pouco válida) como a outra.

Quanto à precisão dada por M.S. de que a ocupação romana de Azenha da Misericórdia tem de ser considerada vestigial, não se vê onde está a incorrecção de M.C.L., visto que esta diz: "Do período romano apenas se encontraram dois fragmentos de tegulae e terão sido recolhidas asas de ânfora".

Ainda relativamente ao povoado de Azenha da Misericórdia, acrescenta M.S.: "Também não é correcta a afirmação de que existem 
duas fornalhas - no povoado existem várias fornalhas metalúrgicas". Se existem várias, existem pelo menos duas. A informação de M.C.L. não é, pois, propriamente incorrecta. Mas peca por defeito. Neste caso, é útil o complemento de informação dado por M.S., pois o povoado adquire maior importância como centro metalúrgico - importância que M.C.L., todavia, implicitamente reconheceu ao falar da "grande quantidade de escória" que se observa no local.

Quanto a S. Brás 1 (n. $\left.{ }^{\circ} 346\right)$, ao qual M.C.L. atribui "uma ocupação desde o Calcolítico até à Idade do Bronze Final”, diz M.S. que isso não corresponde exactamente ao observado na escavação arqueológica realizada por Rui Parreira. Efectivamente, este último registou uma ocupação do Calcolítico e do Bronze Final, mas considerou que "terá de ficar em aberto a possibilidade de um povoamento contínuo até à Idade do Bronze recente".

8. Dúvidas derivadas do facto de M.C.L. não ter conseguido localizar com rigor certas estações arqueológicas referenciadas por outros autores ou não ter observado o que outros autores viram

Sendo numerosas, na obra de M.C.L., as estações inéditas e muitas, também, as que já estavam referenciadas em trabalhos de outros autores (muitas vezes, sem indicação de coordenadas geográficas) mas que agora aparecem correctamente posicionadas e com mais informação, o Catálogo de Sítios inclui algumas que a autora, apesar de intensas buscas, não reencontrou. M.S. refere-se a duas destas: Castelo das Guerras (569) e Folha de Ranjão (33).

Quanto à primeira, referiu-se-lhe Olívio Caeiro, mas sem indicar coordenadas e sem dar indicações precisas sobre a posição do sítio arqueológico. M.C.L. não conseguiu localizar a estação e por isso incluiu-a no seu catálogo com dúvidas expressas sobre a identificação da freguesia e sobre a sua funcionalidade, admitindo, em função da quantidade de sigillata itálica apresentada por aquele autor, tratar-se de villa.

As precisões que M.S. agora presta sobre o sítio são muito úteis, mas é abusivo ver erro onde não há afirmação, visto que M.C.L. manifesta dúvidas sobre a integração administrativa e a funcionalidade do sítio. Quanto a esta, permanecem as dúvidas, dado que M.S. classifica o Castelo das Guerras como habitat e esta designação é demasiadamente abrangente para ser de alguma utilidade. 
Ainda quanto ao Castelo das Guerras, é útil a informação, prestada por M.S., de que entregou, ao Museu de Moura, há mais de uma dezena de anos, os fragmentos de sigillata que M.C.L. refere dizendo que "pertencem à colecção do engenheiro Monge Soares".

M.C.L. também não conseguiu localizar o sítio de Folha do Ranjão (33). Esteve num "monte" com esse nome, mas aí só viu materiais cerâmicos recentes. Abusivamente, M.S. escreve: "lamenta-se que Conceição Lopes não reconheça materiais pré e proto-históricos. O "lamento" - que é, afinal, uma acusação de ignorância - não tem justificação senão na má-fé de M.S. Qualquer crítico honesto admitiria duas hipóteses: ou que M.C.L. não encontrou a estação arqueológica e a procurou em sítio errado, ou que, no(s) momento(s) da(s) visita(s), não eram visíveis, à superfície, senão materiais cerâmicos recentes.

Diga-se, todavia, e em abono da verdade (ou da imparcialidade) que a redacção dada por M.C.L. à sua "ficha" deste sítio não foi feliz, pois pode ser lida como dúvida sobre a correcção das "referências de localização" ou da "descrição" de A. M. Faria e A. M. M. Soares, que revelaram o sítio.

Contesta M.S. as dúvidas de M.C.L. sobre o sítio de Ermida de Nossa Senhora das Pazes 1 (n. ${ }^{\circ} 423$ ). O autor confirma a existência de muros que se observam junto da capela e desaparecem por baixo da ermida e declara ter encontrado aí "alguns materiais romanos ou tardo-romanos". Supõe tratar-se de um casal. M.C.L., incluindo o sítio no catálogo, classifica-o, com muitas dúvidas, como villa, atendendo a informações orais de populares sobre a importância dos achados; mas, por ter assistido a uma escavação da Junta de Freguesia de Vila Verde de Ficalho no local e não ter visto quaisquer materiais romanos, observa que se trata de "sítio a confirmar".

Onde está, neste caso, o erro? Quando muito, M.S. poderia ter incluído este sítio numa lista de "estações de cuja existência ou natureza M.C.L. duvida, considerando necessária uma confirmação" e ter acrescentado que as dúvidas se não justificam, porque é inequívoca a existência de estruturas romanas. Observaremos, todavia, que a anterioridade dos muros relativamente à capela não prova a cronologia romana dessas estruturas. Mas também não temos razões sérias para supor que M.S. se enganou ao classificar como "romanos ou tardo-romanos" alguns materiais que aí encontrou. 


\section{Erros de grafia nos topónimos}

Anota M.S. apenas um: Ervancos, em lugar da correcta grafia Ervanços. Aliás, segundo M.S., o topónimo correcto será Vale de Ervanços.

\section{Sítio cuja existência M.S. contesta}

Trata-se de Pocilgões (n. ${ }^{\circ}$ 431), referenciado em Arqueologia do concelho de Serpa sob o n. ${ }^{\circ} 275$. Pedro C. Carvalho confirma-nos a existência desta pequena estação arqueológica, denunciada por "pequena quantidade de tegulae e cerâmica comum muito rolada e dispersa por uma área aprox. de $200 \mathrm{~m}^{2}$ ". Há todavia lapso na descrição de M.C.L., que fala de "acessos muito difíceis" quando é certo que o acesso ao local não apresenta qualquer dificuldade.

Para além dos casos que examinámos, aludiremos ainda ao sítio de Talho de Nossa Senhora das Pazes (n. ${ }^{\circ}$ 425). M.C.L. inclui o sítio no seu catálogo mas declara não ter visto a(s) estrutura(s) de que M.S. deu notícia. Não há incorrecção ou erro e o caso é inverso do de Pocilgões: aqui, M.S. não viu o que existe; em Talho de Nossa Senhora das Pazes, foi M.C.L. que não viu o que M.S. observou. Só quem não faz prospecção arqueológica pode surpreender-se com o desencontro de dois diferentes observadores. Muitos sítios, sobretudo pequenos, são visíveis em certas ocasiões e não noutras, dependendo muitas vezes de uma chuvada, de luz no momento em que se faz a visita, do crescimento da vegetação, de uma lavra, etc, etc. - ou, quando se trata de prospecção sistemática conduzida por vários observadores ao mesmo tempo, das distâncias a que esses observadores se colocam uns dos outros.

\section{Conclusão}

Do exame que fizemos, com imparcialidade que nos levou a dar razão a M.S. nos poucos casos em que a tem, concluiremos que só com má-fé se pode dizer o que M.S. afirma a propósito da obra de M.C.L. e o editor da Al-madan pôs em destaque: 
"Perdeu-se uma excelente oportunidade de ficar disponível para a comunidade científica uma base de dados de sítios proto-históricos e romanos, na área da civitas de PAX IVLIA, que pudesse ser manejada com um mínimo de confiança". E acrescenta M.S.: "Tudo isto é lamentável e deveria constituir um exemplo do que não se deve fazer em Arqueologia" (o sublinhado é nosso).

Lamentável é a má-fé e falta de objectividade de M.S. Exemplo do que não se deve fazer é o teor da sua apreciação pretensamente crítica.

Quem ler os comentários de M.S. sem os confrontar com o que M.C.L. efectivamente escreveu poderá pensar que a gravidade dos erros e das incorrecções impede a leitura da obra com um mínimo de confiança. Nem sequer se dará conta de que M.C.L. não apresenta o seu catálogo de sítios como base de dados. Com efeito, escreve a autora (na p. 8): "No geral, ainda que na base de dados a totalidade dos campos esteja preenchida, neste catálogo apenas se apresenta uma selecção de campos que responde por uma lógica de racionalidade de informação". A autora claramente distingue uma base de dados, de um catálogo de sítios. Como também observa, nomeadamente a propósito de sítios do concelho da Vidigueira, a brevidade de algumas descrições justifica-se por ter considerado desnecessário repetir o que se acha escrito em publicações de outros autores, para as quais remete.

M.S. não entendeu a perspectiva que M.C.L. adoptou. Não pretendeu a autora elaborar uma base de dados. Pretendeu fazer um estudo da rede de povoamento e da sua dinâmica ou uma arqueologia da paisagem. Até há poucos anos, o que conhecíamos do Alentejo romano eram cidades (como Pax Iulia ou Ebora Liberalitas Iulia) e villae (como Torre de Palma, Pisões ou S. Cucufate). Mas no Alentejo romano havia numerosos casais - pequenas propriedades de exploração unifamiliar e nele se multiplicam os vestígios de pequenas estruturas que, às vezes, não serão mais do que dependências de villae, mais ou menos distantes das residências dos proprietários: o tugurium de um guardador de vara de porcos ou de rebanho de ovelhas, um abrigo de alfaias, uma choça de lenhadores ou carvoeiros, a mansiúncula rasteira de trabalhadores encarregados da exploração de pedras, minérios ou barros, etc. Se o interesse patrimonial destes sítios é nulo, não deixam de merecer atenção quando se trata de recompor uma paisagem ou tentar reconstituir a vida rural.

O interesse da obra que M.S. não entendeu (talvez por dela apenas ter lido umas tantas fichas do catálogo e de o ter feito com o parti pris 
de encontrar erros e incorrecções) reside nessa luz que M.C.L. começou a lançar sobre um mundo rural muito mais complexo e diversificado, não redutivel às residências dos grandes proprietários. Limitado ao "seu" território de Vila Verde de Ficalho, M.S. não entendeu que um estudo de arqueologia da paisagem e da sua dinâmica tem de ter um quadro geográfico mais amplo, seja ele o de uma civitas romana, seja o de uma "região natural". A grande dimensão da área na qual M.C.L. realizou prospecções até justificaria alguns erros e algumas incorrecções.

Os poucos que existem não são minimamente justificativos da desconfiança dos leitores numa obra que um júri idóneo aprovou, justamente, com distinção e louvor. Tal júri não se limitou a julgar o primeiro volume da obra de Maria Conceição Lopes: julgou-a também pelo Catálogo de Sítios. O júri considerou que o Catálogo de Sítios pode ser manejado com confiança, pois as dúvidas (quando a autora as tinha) foram devidamente assinaladas, designadamente com a indicação "a conferir" e os erros ou incorrecções são, afinal, poucos e menores. 